\title{
Reversing platinum resistance in high-grade serous ovarian carcinoma: targeting BRCA and the homologous recombination system
}

\author{
W. Ruprecht Wiedemeyer ${ }^{1,2} *^{\dagger}$, Jessica A. Beach ${ }^{1,3 \dagger}$ and Beth Y. Karlan ${ }^{1,2}$ \\ 1 Women's Cancer Program, Samuel Oschin Comprehensive Cancer Institute, Cedars-Sinai Medical Center, Los Angeles, CA, USA \\ 2 Department of Obstetrics and Gynecology, David Geffen School of Medicine, University of California Los Angeles, Los Angeles, CA, USA \\ ${ }^{3}$ Graduate Program in Biomedical Sciences and Translational Medicine, Cedars-Sinai Medical Center, Los Angeles, CA, USA
}

\section{Edited by:}

Ben Davidson, Oslo University

Hospital, Norway

Reviewed by:

Blake Gilks, University of British Columbia, Canada

Anne Dørum, Oslo University

Hospital, Norway

*Correspondence:

W. Ruprecht Wiedemeyer, Women's

Cancer Program, Samuel Oschin Comprehensive Cancer Institute,

Cedars-Sinai Medical Center, 8700

Beverly Blvd., Suite 290W, Los

Angeles, CA 90048, USA

e-mail:wiedemeyerw@cshs.org

${ }^{\dagger} W$. Ruprecht Wiedemeyer and Jessica A. Beach have contributed equally to this work.
Resistance to platinum chemotherapy is one of the main factors driving ovarian cancer mortality, and overcoming platinum resistance is considered one of the greatest challenges in ovarian cancer research. Genetic and functional evidence points to the homologous recombination (HR) DNA repair system, and BRCA1 and BRCA2 in particular, as main determinants of response to platinum therapy. BRCA-mutant ovarian cancers are especially sensitive to platinum, associated with better survival, and amenable to poly ADP ribose polymerase inhibitor treatment. Here, we discuss a therapeutic concept that seeks to disrupt HR capacity via targeting of BRCA1 and BRCA2 functionality in order to reverse platinum resistance in BRCA-proficient high-grade serous ovarian cancers (HGSOC). We review the molecular signaling pathways that converge on BRCA1 and BRCA2, their activation status in ovarian cancer, and therapeutic options to modulate BRCA function. Several recent publications demonstrate efficient chemosensitization of BRCA-proficient cancers by combining targeted therapy with standard platinum-based agents. Due to its inherent genomic heterogeneity, molecularly defined subgroups of HGSOC may require different approaches. We seek to provide an overview of available agents and their potential use to reverse platinum resistance by inhibiting the HR system, either directly or indirectly, by targeting oncogenic activators of HR.

Keywords: high-grade serous ovarian cancer, platinum resistance, BRCA1, BRCA2, cyclin-dependent kinases, cyclin E1, cyclin-dependent kinase inhibitors, homologous recombination

\section{INTRODUCTION}

Platinum-based chemotherapy agents, such as cisplatin, have been used in the treatment of ovarian carcinoma since the late 1970s. Cisplatin significantly improved the overall survival (OS) of women with ovarian cancer, leading to its adoption as the backbone of most chemotherapeutic regimens $(1,2)$. Carboplatin, a cisplatin analog, with an improved toxicity profile and equivalent therapeutic efficacy has replaced cisplatin as a standard of care since the mid-1980s (3). The next major advance in chemotherapy for epithelial ovarian cancer occurred with the introduction of the mitotic inhibitor paclitaxel, which further improved OS when combined with platinum $(4,5)$. Despite these advances, tumor recurrences still occur in the majority of ovarian cancer patients and cures remain too infrequent.

Epithelial ovarian cancer is a heterogeneous disease with multiple histological subtypes and multiple subclones even within a given patient's tumor. High-grade serous ovarian cancer (HGSOC) accounts for the majority of epithelial ovarian cancers $(68 \%)$. A recent comprehensive analysis by The Cancer Genome Atlas (TCGA) revealed HGSOC to be highly genomically unstable with TP53 gene mutations in more than $96 \%$ of cases, and less frequent mutations in BRCA1 and BRCA2, while mutation frequencies for all other genes are each $<5 \%$ (6). Other ovarian cancer subtypes, such as clear cell and endometrioid ovarian cancers have fewer TP53 mutations and are not commonly associated with $B R C A$ gene mutation $(7,8)$. In addition, TCGA identified a plethora of recurrent DNA copy number changes affecting known oncogenes and tumors suppressor genes. The genomic complexity of HGSOC may explain previous failures of targeted therapy approaches in unselected patient populations. HGSOC has a poor prognosis likely due to a combination of factors, including late stage at presentation and the development of chemoresistance (9). Most patients with advanced (stage III and IV) HGSOC undergo cytoreductive surgery followed by combination platinum- and taxane-based chemotherapy $(4,5)$. While initial response rates are quite high $(\sim 80 \%)$, the majority of patients ultimately relapse due to the emergence of chemoresistant disease (10). Once patients develop resistant disease, the options for effective salvage treatment are limited. Clinical trials investigating the inclusion of alternative chemotherapeutic and biologic agents in recurrent platinum-resistant ovarian cancer have failed to demonstrate significant improvements in OS (11), and the 5-year survival rate has remained relatively unchanged at $43 \%$ for several decades (12). Thus, there is a critical need to identify and understand the molecular mechanisms and biological pathways that contribute to platinum resistance in HGSOC. 
Upon entering a cell, platinum-based compounds generate inter- and intra-strand DNA adducts that activate the DNA damage response (DDR) and subsequently induce DNA repair (13). In the absence of a functional DNA repair system, damage accumulates and cell death ensues. Here, we discuss a therapeutic concept that seeks to reverse platinum resistance in HGSOC via targeting the DNA homologous recombination (HR) repair pathway and the $B R C A 1$ and $B R C A 2$ genes in particular. We will review the role of BRCA1 and BRCA2 in determining the platinum response of the cell as well as the concept of synthetic lethality that has led the introduction of poly ADP ribose polymerase (PARP) inhibitors for the treatment of BRCA-mutant HGSOC. We will then outline pharmacological strategies to mimic "BRCAness" in BRCA-wildtype HGSOC and explore the use of molecularly targeted agents to exploit this pathway and sensitize the cell to platinum-induced lethality.

\section{DNA REPAIR PATHWAYS AND PLATINUM RESISTANCE}

Platinum resistance is a complex phenotype characterized by decreased platinum uptake, increased metabolic turnover, inhibition of pro-apoptotic signals, and restored DNA repair capacity [reviewed in Ref. $(14,15)]$. Due to this complexity, the development of chemoresistant disease is assumed to be a dynamic process involving multiple mechanisms. As DNA alkylating agents, the cytotoxic effects of platinum drugs are largely dependent on the cell's ability to detect and repair DNA damage. Several DNA repair pathways exist and have been linked to platinum resistance. Nucleotide excision repair (NER) is the primary pathway used for intrastrand platinum adduct removal and is an important mediator of responsiveness to platinum-based chemotherapy (16). High NER activity is correlated with platinum resistance $(17,18)$. The mismatch repair (MMR) system functions to repair single-base pair mismatches and erroneous insertions and deletions that occur during DNA replication and recombination. Mutation and decreased expression of MMR components, MLH1 and $\mathrm{MSH} 2$, have been documented in ovarian and other cancers, and correlated with prognostic indicators including chemotherapy response $(19,20)$. In ovarian cancer, deficiencies in MMR and subsequent microsatellite instability (MSI) are estimated to account for tumor development in $<10 \%$ of cases (20). However, the role of MMR inactivation and MSI in platinum response in HGSOC remains controversial, as several studies have reached conflicting conclusions $(21,22)$.

The most lethal lesions induced by platinum agents are DNA double strand breaks (DSBs), which are a result of platinuminduced interstrand crosslinks. These DSBs are particularly toxic as both strands of DNA are affected and there is no intact complimentary strand to utilize as a template for repair. DSBs are repaired by two major pathways within the cell: non-homologous end-joining (NHEJ) and HR. The preferred method of DSB repair is $\mathrm{HR}$, as NHEJ is inherently mutagenic and can result in undesirable insertions and/or deletions. HR is a highly conserved pathway that provides error-free repair of DSBs by using the intact sister chromatid as a template, which fixes the break while maintaining sequence integrity. Due to this requirement, $\mathrm{HR}$ occurs during $\mathrm{G}_{2}$ and S phases of the cell cycle (23). Two of the most well-known HR proteins are BRCA1 and BRCA2. BRCA1 is a multipurpose protein that participates in DDR activation, cell cycle checkpoint initiation, and DSB repair as a component of several supercomplexes (24). In HR, BRCA1 is localized to DSBs through its association with the abraxas-RAP80 complex, and promotes $5^{\prime}$-end resection of the break in cooperation with other proteins $(25,26)$. BRCA1 is also required in the later stages of $\mathrm{HR}$, where its interaction with PALB2 and BRCA2 is necessary for the recruitment of RAD51 to DSBs and subsequent strand invasion of the sister chromatid for DNA repair $(27,28)$. Of note, the only well-documented function of BRCA2 is its direct binding of RAD51 in HR (29).

\section{THE BRCA PARADOX}

Mutations in BRCA1 or BRCA2 are found in the majority of hereditary breast and ovarian cancers and greatly increase lifetime risk for both cancers. Moreover, somatic mutations in at least one of the $B R C A$ genes are present in a significant proportion of sporadic HGSOC, rendering $B R C A 1$ and $B R C A 2$ as two of the most frequently mutated tumor suppressor genes that guard against the transformation of serous epithelium to HGSOC. However, once an advanced tumor has developed, BRCA-mutant HGSOC are associated with better survival than wildtype HGSOC. This seeming paradox was first described by comparing outcomes of women with hereditary epithelial ovarian cancer to those of women with sporadic ovarian cancer. $B R C A$ mutation carriers had significantly prolonged survival compared to patients with sporadic disease $(30,31)$. A meta-analysis of 26 studies comparing 1213 cases with germline BRCA mutations and 2666 non-carriers determined that the 5 -year survival rate was $36 \%$ for non-carriers, $44 \%$ for $B R C A 1$ mutation carriers, and $52 \%$ for BRCA2 mutation carriers (32). Further, the analysis by TCGA of 316 HGSOC confirmed that $B R C A$-mutant HGSOC (both hereditary and sporadic) are associated with better survival than BRCA-wildtype HGSOC (6). Collectively, these studies suggest that $B R C A$-deficient HGSOC respond better to standard therapies, specifically platinum chemotherapy, compared to BRCA-wildtype cancers, and further, that an intact HR system seems to be crucial for the survival of platinum-treated ovarian cancer cells.

\section{RESTORED BRCA FUNCTION IN PLATINUM-RESISTANT CANCERS}

An independent line of evidence supporting intact BRCA and HR function as one of the main determinants of chemosensitivity emerged from the analysis of platinum-resistant cells in which BRCA function had been restored by secondary mutations. Sakai et al. analyzed cisplatin-resistant subclones of the CAPAN1 pancreatic cancer cell line, which carries a 6174delT frame-shift mutation and lacks wildtype BRCA2 (33). Fifty percent (7/14) of the resistant clones had restored expression of BRCA2 by intragenic deletions, insertions, or deletions/insertions. In all clones, the reading frame had been restored, and a functional protein was expressed. Similarly, frame-shift mutations in the BRCA1 gene can be reversed by secondary mutations in cisplatin-resistant ovarian cancers $(34,35)$. Mechanistically, secondary mutations could be the result of error-prone DNA repair in cells that lack a functional HR system. In the presence of cisplatin, cancer cells with restored HR function are expected to have a strong selection advantage and may thus become the dominant cell clone in recurrent cancers. In a mouse model of mammary tumorigenesis induced by combined 
loss of Brcal and $p 53$ (K14-Cre; Brcal $1^{\text {flox/flox }}$; p53 $3^{\text {flox/flox }}$ ), Brca1null tumors do not become cisplatin-resistant over the course of at least six cycles of cisplatin treatment (36). In contrast to point mutations or small insertions/deletions found in human cancers, large genetic deletions resulting from Cre-mediated recombination in this mouse model are irreversible. The inability of these murine cancer cells to restore functional Brcal expression may explain their sustained platinum sensitivity. Interestingly, platinum treatment cannot fully eradicate the breast tumors in this model, leaving a small fraction of surviving cells that can repopulate the tumor following withdrawal of cisplatin (36). It is tempting to speculate that the few surviving clones escape from platinum-induced death by employing mechanisms related to reduced proliferation, such as acquisition of cancer stem cell properties, or complete exit from the cell cycle [dormancy, reviewed in Ref. (37)].

\section{EXPLOITING LOSS OF BRCA FUNCTION IN A SYNTHETIC LETHAL APPROACH USING PARP INHIBITORS}

Synthetic lethality is defined as death resulting from concomitant mutation of two genes if mutation of either gene alone is associated with viability but mutation of both is lethal (38). This concept can be expanded to more than two genes and to pharmacologically modulated gene activity, e.g., loss-of-function following pharmacological inhibition of protein that is critically required in cancer cells. In the context of anticancer therapy, a synthetic lethal approach may take advantage of somatic mutations that render the tumor sensitive to specific chemotherapeutic agents but spare normal cells without the mutation. Alternatively, tumor-specific dependency on individual genes or signaling pathways ("oncogene addiction") can expose synthetic lethal vulnerabilities.

In ovarian cancer, the most prominent example of synthetic lethality involves PARP inhibition in BRCA-mutant cancers. PARP is a DNA repair enzyme and part of the base excision repair (BER) pathway. The HR defect in BRCA-mutant cancers renders them particularly sensitive to inhibition of other DNA repair pathways that compensate for loss of HR activity. Concomitant defects in the HR and BER pathways are synthetic lethal; DNA damage accumulates in PARP inhibitor-treated BRCA-mutant cells and may be repaired by error-prone mechanisms, such as NHEJ. As a result, complex chromatid rearrangements ensue that lead to $\mathrm{G}_{2} / \mathrm{M}$ phase cell cycle arrest and subsequent cell death (39).

Based on the concept of synthetic lethality, several PARP inhibitors (PARPi), such as Olaparib, have entered clinical trials for ovarian cancer and other BRCA-associated cancers. Ovarian cancer-specific trials in patients with recurrent $B R C A$-mutant cancers showed high response rates between 30 and $60 \%$ for Olaparib $(40,41)$ and increased progression-free survival (42). While $B R C A$-mutant cancers are especially sensitive to PARPi, a significant proportion of BRCA-proficient HGSOC are thought to exhibit a "BRCAness" phenotype, which is caused by HR defects other than BRCA mutation (43). HGSOC with the BRCAness phenotype are also predicted to be sensitive to PARPi, and the identification of these cancers within the pool of BRCAwildtype HGSOC could increase the proportion of PARPi-eligible patients.

\section{TARGETING HR FUNCTION AS A CHEMOSENSITIZATION STRATEGY}

In addition to identifying cancers with inherent HR defects, the active modulation of HR capacity in BRCA-proficient cancers via targeting of BRCA function is an attractive therapeutic concept. Quinn et al. showed that downregulation of BRCA1 by RNAi increased sensitivity to cisplatin in ovarian cancer cell lines (44), thus providing a rationale for the use of pharmacological agents in order to inhibit BRCA function. Several recent publications suggest that pharmacological targeting of BRCA1 and BRCA2 can sensitize $B R C A$-wildtype cancers to platinum-based chemotherapy and PARP inhibition. In the following sections, we will outline potential therapeutic strategies that target BRCA loss-of-function as a result of transcriptional downregulation or inhibition of protein activity. We will describe the molecular pathways regulating $B R C A$ gene expression and their activation in HGSOC, and the transcription factors that mediate transcriptional activation of $B R C A 1$ and BRCA2. Finally, we will discuss different classes of targeted compounds for their potential use as chemosensitizing agents in BRCA-proficient HGSOC. We hypothesize that molecular targeting of HR function can reverse platinum resistance in HGSOC.

\section{REGULATION OF BRCA1 AND BRCA2}

Control of BRCA1 and BRCA2 activity involves transcriptional regulation and post-translational modifications of the BRCA proteins. As part of the DDR, BRCA1 is phosphorylated by CHEK2 and ATM in normal cells and cancer cells following irradiation or exposure to alkylating agents [reviewed in Ref. (24)]. While DDR inhibitors may be able to sensitize cells to DNA-damaging agents, this article focuses on targeting genes and pathways that are activated specifically in cancer cells and required for BRCA gene expression and/or activity. Importantly, many oncogenic drivers and their downstream mediators, such as proliferation-associated transcription factors, are positive regulators of $B R C A 1$ and $B R C A 2$. Activation of BRCA1 and BRCA2 by oncogenes offers the opportunity to selectively sensitize cancer cells to platinum by targeting defined genetic alterations that are not present in normal cells. Inhibition of oncogenic drivers may result in downregulation of $B R C A$ mRNA and/or inactivation of BRCA proteins.

BRCA1 and BRCA2 are regulated in a cell cycle-dependent manner. In cultured cells, BRCA1 and BRCA2 mRNA expression is low under conditions of serum starvation, confluency, or other factors that induce $\mathrm{G}_{0}$ cell cycle arrest $(45,46)$. In contrast, rapidly proliferating cells express high levels of both BRCA1 and BRCA2 mRNA. This is in line with the documented function of BRCA1 and BRCA2 in HR, which occurs during the $S$ and $G_{2}$ phases of the cell cycle, and ensures DNA replication fidelity.

\section{Transcriptional regulation of BRCA1 and BRCA2 by ETS, MYC, and E2F}

Several classes of transcription factors are involved in cell cycle progression and have been shown to regulate $B R C A 1$ and $B R C A 2$ expression. Initial analysis of the human $B R C A 1$ promoter identified a core promoter region that extends from about $250 \mathrm{bp}$ upstream of the transcription start site (TSS) into the first exon (47, 48 ). This $<300 \mathrm{bp}$ region, which was associated with the highest 


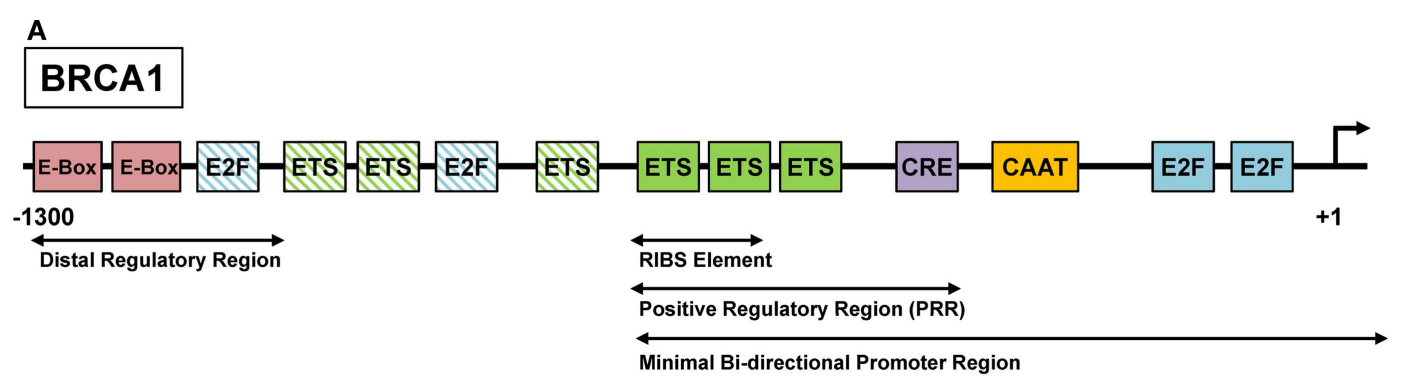

B

BRCA2

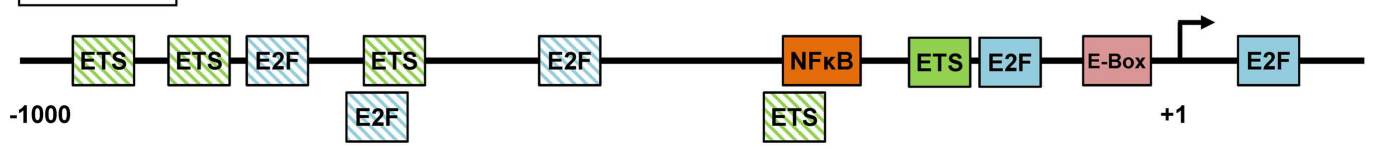

FIGURE 1 | ETS, MYC, and E2F regulate the BRCA1 and BRCA2 promoters. (A) The regulation of the BRCA1 promoter is complex and several regulatory sites have been identified. The positive regulatory region (PPR) located at the $5^{\prime}$ end of the promoter has been shown to be necessary and sufficient for BRCA1 transcription, and contains sites such as the cyclic-AMP response element (CRE). Within the PPR, the three consecutive ETS factor binding sites are known as the RIBS element and have been shown to be bound by GA-binding protein $\alpha / \beta(\mathrm{GABP} \alpha / \beta)$, an ETS factor family member. (B) The BRCA2 promoter contains several conserved recognition motifs for transcription factors including E-box, E2F, and ETS (49). BRCA2 gene transcription may be activated by the binding of ELF1, an ETS factor, to the ETS recognition motifs or by the binding of USF1 and USF2, basic helix-loop-helix leucine zipper family members, to the E-box. Additionally, NF-kB can also bind the BRCA2 promoter and induce genes expression (59). Functionally characterized binding sites are depicted by solid colored boxes. Putative binding sites are depicted by patterned boxes and were identified using the MatInspector software (Genomatix, Munich). Diagrams are not drawn to scale. promoter activity in reporter assays, contains several E2F and ETS binding sites as well as a CREB binding site (Figure 1A). The human BRCA2 promoter has been characterized to a lesser extent but also contains functionally relevant E2F and ETS binding sites within its proximal region (Figure 1B) (49). Traditionally, E2F transcription factors are considered as the main mediators of $\mathrm{G}_{1}-$ $S$ progression. Activator E2Fs (E2F1-3) transcribe many of the genes involved in DNA replication, checkpoint control, and DNA repair (50). Importantly, E2F function couples proliferation and DNA repair by coordinating the induction of genes required for DNA synthesis, such as thymidine kinase (TK1) and dihydrofolatereductase (DHFR), and DNA repair, such as BRCA1, BRCA2, and RAD51 (51). However, mouse models have demonstrated that while activator E2Fs are critical for cell cycle progression in some cell systems, E2F-independent proliferation occurs in others (5254). There is mounting evidence that other classes of transcription factors can compensate for loss of E2F function in some cell types. For example, E2f1-3-null mouse retinal progenitor cells continued to divide possibly due to compensation by Mycn, a member of the MYC family of basic helix-loop-helix transcription factors (52). In breast cancer cells, MYC was found to directly regulate the $B R C A 1$ promoter via binding to distal regulatory regions (55) (Figure 1A). In addition, oncogenic ETS family transcription factors were shown to induce a subset of E2F target genes $(56,57)$, including BRCA2 (58). Thus, a number of cancer-relevant transcription factors regulate $B R C A 1$ and $B R C A 2$. In order to achieve effective downregulation of $B R C A$ transcription, it is necessary to identify and target the main drivers of $B R C A$ gene expression in different subgroups of HGSOC.

\section{Pharmacologic targeting of oncogenic transcription factors driving BRCA expression}

Some of the transcription factors driving $B R C A$ gene expression are known oncogenes $(M Y C)$ or putative oncogenes in ovarian cancer, based on functional data and evidence of genetic activation in primary HGSOC: MYC is amplified in 30\% of HGSOC (6), and E2F3 is amplified in about $10 \%(60)$. While most transcription factors are not easily druggable with currently available agents, targeting of BET bromodomain proteins has been described as an effective means of inhibiting MYC-dependent transcription (61). Preclinical studies with the small molecule inhibitor JQ1 have yielded promising results in MYC-dependent hematologic malignancies, medulloblastoma (62), and KRAS-mutant lung cancer (63), but its compatibility with platinum-based chemotherapy, as well as its effect on BRCA gene expression, has yet to be established.

ETS family transcription factors have been implicated in platinum resistance. ETS1 was shown to be overexpressed in $\mathrm{C} 13$ cells, a cisplatin-resistant derivate of 2008 ovarian cancer cells (64), and ectopic expression of ETS1 in 2008 cells conferred platinum resistance. Similarly, ETV4 (PEA3) is overexpressed in cisplatinresistant PEO1 ovarian cancer cells (65). Both the BRCA1 and the $B R C A 2$ promoter are bound and activated by ETS transcription factors: GA-binding protein $\alpha / \beta(\mathrm{GABP} \alpha / \beta)$ binds the RIBS element in the BRCA1 core promoter (Figure 1A), and overexpression of $\mathrm{GABP} \alpha / \beta$ in breast cancer cells was able to stimulate $B R C A 1$ promoter activation (66). Similarly, BRCA2 gene transcription may be activated by the binding of ELF1, another ETS family member (49) (Figure 1B). 


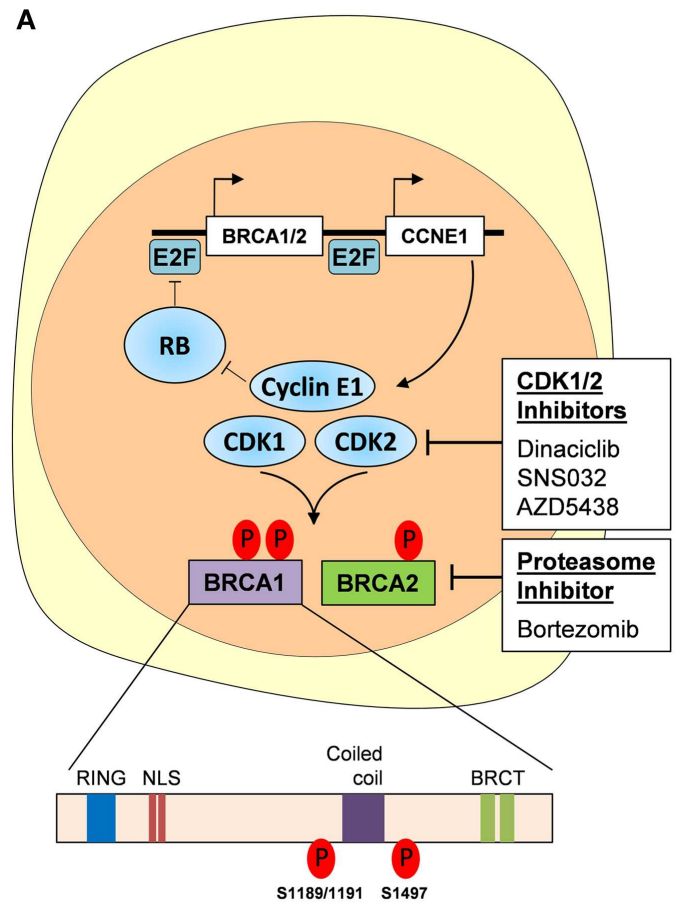

FIGURE 2 |Targeting cyclin E1-dependent ovarian cancers. (A) Cyclin E1 function is dependent on it interaction with CDK1 and CKD2. CDK1/2 inhibitors inhibit this interaction and cause E2F-mediated transcriptional downregulation of BRCA1 and BRCA2. CDK1/2 inhibition may also prevent their phosphorylation and subsequent activation of the BRCA1 and BRCA2 proteins. Alternatively, use of Bortezomib, a proteasomal inhibitor, can inhibit HR function and potentially sensitize cyclin E1-dependent tumors to platinum-based chemotherapy. NLS, nuclear localization signal; BRCT, BRCA1 C-terminus domain. (B) Kaplan-Meier curve showing that $C C N E 1$ overexpression ( $n=32$ tumors, $Z$-score $\geq 2$ ) in HGSOC was associated with significantly reduced overall survival (OS) as compared with tumors with normal or low expression of CCNE1 $(n=97$

Studies in prostate cancer suggest a targeting strategy for oncogenic ETS factors. Constitutive activation of ERG, ETV4, or ETV5 following gene fusion with the TMPRSS2 promoter renders the fusion gene oncogenic in prostate cancer cells (67). ERG was shown to interact with PARP and require PARP activity for its transcriptional activity. Inhibition of PARP by Olaparib specifically sensitized ERG-driven prostate cancer xenograft to the alkylating agent, temozolomide (68). Similarly, ETS-dependent, BRCA-proficient ovarian cancers may be susceptible to PARPi. However, ETS gene fusions have not been detected in ovarian cancer, and biomarkers of ETS dependency have yet to be identified in HGSOC. Thus, direct targeting of transcription factors is an interesting therapeutic strategy, but requires additional studies prior to translation into the clinic.

\section{REGULATION OF BRCA1 AND BRCA2 BY ONCOGENIC SIGNALING}

A more immediate option may present itself in targeting the signaling pathways that lead to activation of transcription factors. ETS, MYC, and E2F transcription factors are downstream

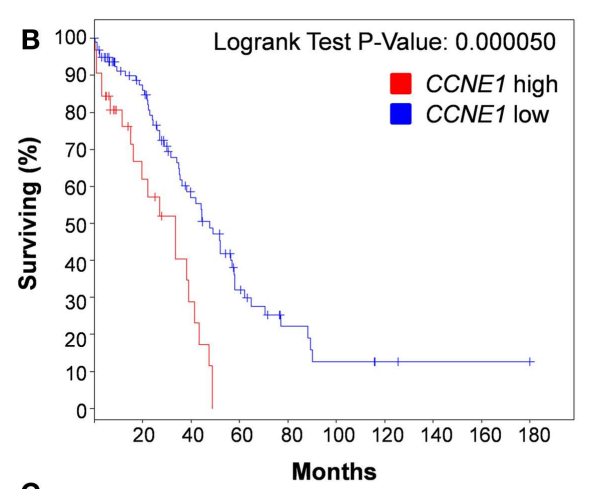

C

\begin{tabular}{cccc}
\hline $\begin{array}{c}\text { Gene } \\
\text { Name }\end{array}$ & $\begin{array}{c}\text { Median } \\
\text { Z-score High }\end{array}$ & $\begin{array}{c}\text { Median } \\
\text { Z-score Low }\end{array}$ & p-value \\
\hline CCNE1 & 3.1635 & -0.2718 & $3.88 \mathrm{E}-12$ \\
BRCA1 & 0.0654 & -0.5358 & $3.06 \mathrm{E}-08$ \\
BRCA2 & 0.4077 & -0.5749 & 0.0069 \\
RAD51 & 0.0443 & -0.4135 & 0.0013 \\
XRCC2 & 1.0171 & -0.0302 & 0.0006 \\
E2F1 & 0.8970 & -0.0972 & $2.69 \mathrm{E}-06$ \\
BIRC5 & 0.1416 & -0.5556 & 0.0001 \\
CDK1 & 0.3572 & -0.4719 & $1.20 \mathrm{E}-05$ \\
TK1 & 0.0494 & -0.3606 & 0.0442
\end{tabular}

tumors, Z-score <2). Median OS for cancers with CCNE1 high and normal/low expression were 33.44 and 47.47 months, respectively. $A$ subset of 129 HGSOC tumors from the TCGA dataset was used for this analysis and was selected based on p53-mutant and BRCA1-and BRCA2-wildtype status as well as availability of RNAseq V2 data. Data were accessed using the $\mathrm{cBioPortal}$ for Cancer Genomics maintained by the Computational Biology Center at Memorial Sloan-Kettering Cancer Center. (C) Increased expression of HR and DNA repair-related genes in cyclin E1-overexpressing tumors. Known E2F targets, E2F1, BIRC5 (survivin), CDK1 (CDC2), and TK1 are included for reference. Median $Z$-score values for each $C C N E 1$ expression subset are shown; $P$ values were determined using Student's $t$-test.

mediators of several oncogenic signaling pathways (Figures 2A and 3). Inhibition of these pathways may result in loss of transcriptional activity and subsequent downregulation of $B R C A$ gene expression. TCGA identified the retinoblastoma (RB) pathway, phosphatidylinositide 3-kinase (PI3K), and RAS signaling as the most frequently altered signaling pathways in HGSOC (6).

\section{The RB pathway}

The RB pathway governs $G_{1} / S$ transition in mammalian cells. In proliferating cells, growth factor or oncogene-induced expression of cyclin $D$ results in activation of the cyclin-dependent kinases, CDK4/6, and inactivation of the RB protein. RB forms complexes with E2F1-3 proteins and inhibits their transactivating activity. Phosphorylation of $\mathrm{RB}$ by $\mathrm{CDK} /$ cyclin complexes unleashes $\mathrm{E} 2 \mathrm{~F}$ activity, resulting in expression of E2F target genes, including cyclin E1 (CCNE1), CDK2, and E2F1-3, which amplify the signal in a positive feedback loop and transition the cell from $G_{1}$ to $S$ phase. The CDK/cyclin-RB-E2F axis (RB pathway) is frequently 


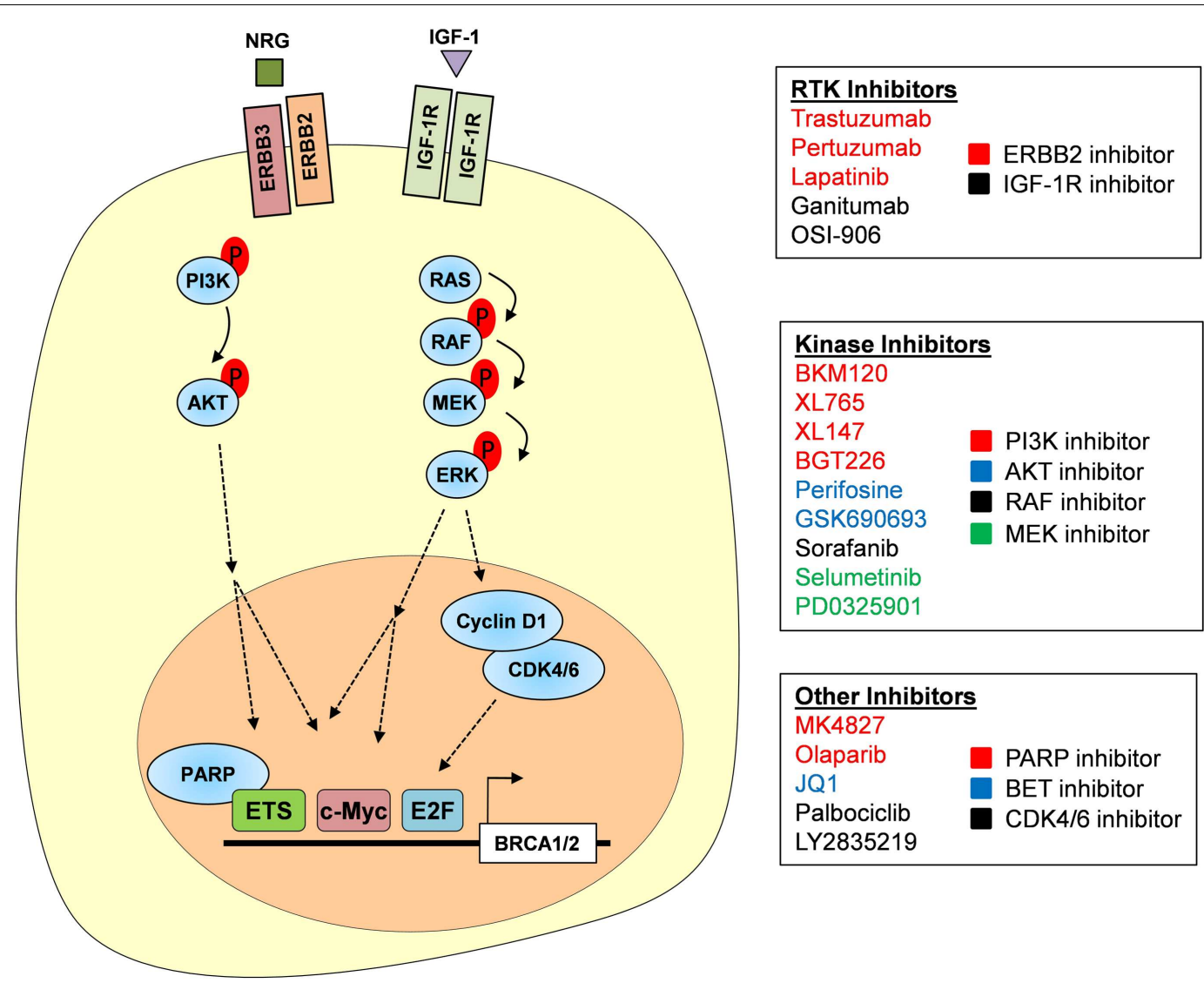

FIGURE 3 | Targeting the RTK-PI3K/MAPK axis. RTKs, including ERBB2/ERBB3 and IGF-1R, are activated by their respective growth signals and are capable of signaling through both the PI3K-AKT and MAPK pathways. Subsequent activation of AKT and ERK allows for the phosphorylation of multiple transcription factors including ETS and MYC that are important in $B R C A 1$ and BRCA2 gene transcription. Activation of ERK also induces cyclin
D1 production, which in complex with CDK4/6 promotes E2F-mediated gene transcription. We propose that BRCA1 and BRCA2 expression could be inhibited at each of these levels; inhibitors of RTKs, PI3K signaling, MAPK signaling, and CDK4/6 are listed. PARPi, such as Olaparib, may also downregulate BRCA gene expression as PARP1 is required as a co-factor for some ETS family members. deregulated in cancer as a result of mutations or deletions in RB1 (10\% in HGSOC), amplification of cyclin genes (CCNE1 is amplified in $20 \%$ of HGSOC, CCND1 is amplified in $4 \%$ ), or functional loss of endogenous $\mathrm{CDK}$ inhibitors (CDKi), such as p16 ${ }^{\text {INK4A }}$ (CDKN2A, downregulated in $30 \%$ of HGSOC) (6). The net result of $\mathrm{RB}$ pathway alterations in cancer is increased proliferation and elevated E2F activity compared to normal tissue. Wang et al. studied regulation of the murine Brcal promoter by the CDK/cyclin-RB-E2F axis. Using a luciferase Brcal promoter construct ( +6 to -1003 ), ectopic cyclin D1 induced luciferase activity while RB suppressed activity. They also identified a conserved 5'-GCGGGAAT-3' E2F binding site at -37 to -19 relative to the TSS ( -23 to -5 in the human BRCA1 promoter) and demonstrated physical binding of E2F protein to this region (69) within the BRCA1 core promoter (Figure 1A). Hence, the $\mathrm{RB}$ pathway directly controls $B R C A$ expression via regulation of E2F activity, and targeting of cancer-specific RB pathway lesions, such as CCNE1, may result in downregulation of BRCA gene expression.

\section{TARGETING CCNE1 DEPENDENCY}

\section{Direct targeting of CDK/cyclin signaling}

CCNE1-amplified cancers make up a large subgroup (20\%) of HGSOC that lack BRCA mutations (6) and are therefore less likely to respond to PARPi. For likely the same reason, CCNE1amplified tumors were reported to be among the most chemoresistant HGSOC (70), and recurrent CCNE1-amplified HGSOC continue to be dependent on the presence of the CCNE1 amplicon (71). The CCNE1 gene product, cyclin E1, is a co-factor for cyclin-dependent kinases 1 and $2(\mathrm{CDK} 1 / 2)$ and activates $B R C A 1$ and $B R C A 2$ transcription via E2F transcription factors (50) (Figure 2A). Therefore, CCNE1-amplified HGSOC often express high levels of wildtype BRCA1 and exhibit an "antiBRCAness" phenotype in terms of their relative resistance to platinum chemotherapy. Using the TCGA dataset, we show that cyclin E1-overexpressing, BRCA-wildtype HGSOC have significantly reduced OS compared to $B R C A$-wildtype cancers with lower cyclin E1 expression (Figure 2B). This suggests that high levels of cyclin E1 confer an added advantage to BRCA-proficient 
cancers. We attribute this, at least in part, to increased expression of several HR genes, including BRCA1, BRCA2, RAD51, all of which have significantly higher RNA levels in cyclin E1-overexpressing cells (Figure 2C).

CDK inhibitors may be a therapeutic option for cyclin E1dependent HGSOC, including CCNE1-amplified cancers. Cyclin E1 has the highest affinity for CDK2, its main binding partner in actively cycling cells (72-74), and CDK1 (CDC2) (75). Both CDK2 and CDK1 directly phosphorylate $\operatorname{BRCA1}(76,77)$ (Figure 2A). Furthermore, a functional link between CDK1 and BRCA1 has been established in lung cancer. Using an inducible shRNA targeting CDK1 in a human non-small cell lung cancer cell line, Johnson et al. showed that CDK1 contributes to S phase checkpoint control following DNA damage (77). CDK1 directly phosphorylated BRCA1 at several serine residues and is required for the formation of BRCA1 foci following DNA damage. Genetic depletion or pharmacological inhibition of CDK1 sensitized BRCA1-proficient cancer cell lines to cisplatin (77) and PARPi (78). Similarly, BRCA2 is phosphorylated by both CDK1 and CDK2 (79).

While there are still no selective inhibitors of CDK1 or CDK2, latest generation CDKi have increased specificity and potency compared to early CDKi, such as flavopiridol, which failed in the clinic. The compound Dinaciclib inhibits CDK1/2/5/9 at low nanomolar concentrations ( $\mathrm{IC}_{50}$ values: $\mathrm{CDK} 1: 3 \mathrm{nM}, \mathrm{CDK} 2$, $1 \mathrm{nM}$, CDK5: $1 \mathrm{nM}$, CDK9: $4 \mathrm{nM}$ ). It induces apoptosis in model systems and prevents tumor progression in A2780 ovarian cancer xenografts $(80,81)$. We hypothesize that of the currently available CDKi, Dinaciclib may have the best therapeutic potential in cyclin E1-dependent ovarian cancer. Our unpublished data show that Dinaciclib exposure results in downregulation of BRCA1 and $B R C A 2$ and sensitized cyclin E1-dependent ovarian cancer cells to cisplatin. Hence, Dinaciclib may have a dual effect on BRCA1 and BRCA2 by causing E2F-mediated transcriptional downregulation and inhibiting CDK1/2-mediated activation of the BRCA proteins (Figure 2A).

Dinaciclib is currently being evaluated in a phase 3 clinical trial for chronic lymphocytic leukemia (CLL) and may have clinical potential in cyclin E1-dependent HGSOC as a chemosensitizing agent. In order to select eligible patients, CCNE1-amplified cancers can be easily identified by fluorescence in situ hybridization (FISH). Other available CDK2 inhibitors, including Roscovitine, SNS032 (82), and AZD5438 (83), may have similar chemosensitizing potential. CDK1, the only mammalian CDK required for proliferation in all cell types (84), is not inhibited by SNS032, rendering this compound potentially less potent but also less toxic to normal cells. In principle, other CDKi such as the CDK4/6 inhibitor Palbociclib (formerly PD0332991) could be used to reduce BRCA expression in cyclin D-dependent HGSOC. However, Palbociclib was shown to be cytostatic in most systems (85-87) and may thus interfere with the cytotoxic activity of platinum agents.

\section{Targeting of HR components induces synthetic lethality in CCNE1-amplified HGSOC}

An independent approach to target CCNE1-amplified HGSOC identified the proteasome inhibitor, Bortezomib (88). In contrast to $\mathrm{CDKi}$, Bortezomib primarily affects the homologous repair system itself, resulting in synthetic lethality in CCNE1-amplified cancer cells: a genome-wide shRNA screen in 102 cancer cell lines revealed that BRCA1 was specifically required in CCNE1-amplified cell lines. Genetic depletion of BRCA1 resulted in significant loss of viability in CCNE1-amplified cells, including the ovarian cancer cell line OVCAR3, whereas a lesser effect was observed in CCNE1wildtype cells, such as the SKOV3 cell line (88). This suggests a synthetic lethal relationship between CCNE1 amplification and loss of BRCA1 function and provides a potential explanation for the observed mutual exclusivity between CCNE1 amplification and $B R C A$ mutation $(6,89)$. In addition to BRCA1, the shRNA screen identified the DNA repair genes $A T R$ and $X R C C 2$ as specific genetic hits in CCNE1-amplified cell lines, suggesting that inhibition of the DDR may be a therapeutic strategy in CCNE1-amplified ovarian cancer. To this end, the authors tested Bortezomib, a potent inhibitor of the HR system, in a panel of ovarian cancer cell lines and found that CCNE1-amplified lines were most sensitive. While Bortezomib had minimal activity as a single agent in recurrent ovarian cancer $(90)$ combination with platinum resulted in clinical activity (91). As discussed for CDKi, specific selection of patients with CCNE1-amplified cancers for Bortezomib treatment may further increase the response rate.

\section{RECEPTOR TYROSINE KINASE, PI3K, AND RAS SIGNALING}

In addition to genetic aberrations within the RB pathway, several oncogenic signals contribute to cell cycle deregulation and E2F activity. Oncogenic KRAS (amplified in 11\% of HGSOC), MYC, and receptor tyrosine kinases (RTK) all converge on cyclin D and require its function for their oncogenic activity (92-94). Moreover, a synthetic lethal relationship was described for KRAS and CDK4, the binding partner of cyclin D (94). KRAS and ERBB2 signal through the mitogen-activated kinase (MAPK) signaling pathway, which culminates in activation of ERK (Figure 3). Phosphorylation by ERK activates multiple cellular target proteins, including ETS, CREB, and MYC. The molecular link between oncogenic signaling pathways and expression of BRCA1 and BRCA2 offers additional opportunities for therapeutic intervention, including direct targeting of ERBB2 and other RTK, targeting of the MAPK pathway by specific MEK or ERK inhibitors, or targeting of the PI3K-AKT axis by specific inhibitors (Figure 3). However, due to the complex signaling events elicited by RTK and other oncogenic pathways, regulation of $B R C A$ gene expression is only one of many downstream events, some of which may actually interfere with the intended chemosensitizing effect. Functional studies are needed to determine the compatibility of individual targeted agents with platinum and PARPi.

\section{Targeting RTK signaling and downstream pathways}

Although amplifications or mutations of individual RTK are rare events in primary HGSOC (ERBB2 amplification: 3\%, ERBB3 amplification: $<5 \%, I G F 1 R$ amplification: $<4 \%$, Figure 3), altered ERBB receptor signaling and overexpression of the downstream RTK mediator ETV4 were found in cisplatin-resistant PEO1 cells (65). RTK can be targeted directly by small molecule inhibitors (e.g., Lapatinib for ERBB2) or antagonistic antibodies (e.g., Trastuzumab or Pertuzumab for ERBB2). However in unselected patients, the addition of Pertuzumab to 
carboplatin-based chemotherapy did not result in prolonged progression-free survival (95), highlighting the importance of patient selection and companion diagnostics to identify likely responders to RTK inhibitors. Activation of the MAPK and PI3KAKT signaling pathways by RTK, or as a result of amplification, offers additional potential therapeutic targets [also reviewed in Ref. (96)]. Both PIK3CA, the gene encoding the catalytic subunit of PI3K, and the $A K T$ genes are frequently amplified in HGSOC (PIK3CA: 28\%, AKT1: 5\%, AKT2: 8\%, AKT3: 9\%), indicating their oncogenic roles in ovarian cancer. Interestingly, AKT was shown to directly phosphorylate BRCA1 at serine 694 and promote its protein stability (97). A second AKT phosphorylation site at threonine 509 was described but its functional implications are unknown (98).

Functionally, a recent study in triple negative breast cancer demonstrated that PI3K signaling was required for BRCA1 function. Ibrahim et al. showed that inhibition of PI3K phenocopied loss of BRCA1 and induced synthetic lethality in combination with Olaparib (99). Loss of PI3K resulted in reduced BRCA1 expression both in cell line models and in patient-derived tumor xenografts. Combined treatment with BKM120, a small molecule PI3K inhibitor, and Olaparib significantly delayed tumor progression in two out of three xenografts whereas single agent treatment had little effect on tumor progression. On the molecular level, the MAPK pathway mediated the transcriptional effect on BRCA1 via ETS1-dependent downregulation of BRCA1 (99). Interestingly, BKM120 treatment resulted in activation of the MAPK pathway and phosphorylation of ETS1 by ERK, indicating a repressor function for ETS1 in this system. This finding highlights the complexity of BRCA gene regulation and its dependency on genetic context. Due to feedback mechanisms and functional compensation among RTKs, downstream kinases, and transcription factors, specific pharmacological combinations may be limited in their effectiveness to small genetically defined subsets of HGSOC. Moreover, as a result of the genetic complexity and genomic instability that is a hallmark of HGSOC, individual cancers are likely to harbor or develop resistant cell clones to any given combination. Thus, it will be important to identify multiple agents targeting different pathways, all of which should be characterized with respect to: (1) their ability to induce BRCA loss-of-function, (2) their compatibility with platinum and/or PARPi, both in terms of toxicity and mechanism of action, and (3) accompanying biomarkers that allow for careful patient selection.

\section{TARGETING BRCA PROTEIN STABILITY}

A different approach to inhibit BRCA1 function involves targeting of the chaperone protein heat shock protein 90 (HSP90), required for BRCA1 protein stability (100). Interestingly, HSP90AB1 is also amplified in a small subset of HGSOC (6). Specific inhibition of HSP90 in BRCA1-proficient breast cancer cells-induced BRCA1 ubiquitination and proteasomal degradation ultimately resulting in compromised DSB repair by HR. HSP90 inhibition sensitized BRCA1-proficient breast and ovarian cancer cells in vitro to carboplatin treatment at concentrations similar to BRCA1-mutant cells (100). In a subsequent study, treatment with the pan-histone deacetylase complex (HDAC) inhibitors vorinostat or panobinostat induced hyperacetylation of HSP90 gene (HSP90AA1I0), thereby inhibiting its chaperone function and leading to proteasomal degradation and depletion of BRCA1 (101). Of clinical significance, treatment of human triple negative breast cancer cell lines with vorinostat was able to induce BRCA1 degradation and a subsequent BRCAness phenotype, which synergistically induced cell death in combination with PARPi or cisplatin (102). Based on these preliminary studies, it is suggested that treatment of platinum-resistant HGSOC with HDAC inhibitors may also be able to induce a BRCAness phenotype and resensitize these cells to platinum or other targeted agents. Trials evaluating vorinostat as a single agent in recurrent epithelial ovarian cancer showed it had limited activity (103). Vorinostat may show better therapeutic efficacy as a biologic response modifier in combination with platinum-based chemotherapy and trials assessing this use in ovarian cancer are underway.

\section{CONCLUDING REMARIS}

In HGSOC cells, a functional HR system and intact BRCA1 and BRCA2 function are often associated with resistance to platinumbased chemotherapeutic agents and PARPi. A plethora of targeted agents are currently available to modulate BRCA function via transcriptional or post-translational intervention. With the advent of novel diagnostic tools, such as the use of deep sequencing to repeatedly profile cancers throughout their evolution, it should become possible to predict rational therapeutic combinations that prevent or at least delay the onset of platinum resistance and should ultimately result in improvements in OS.

\section{ACKNOWLEDGMENTS}

This work was supported by the Ovarian Cancer Research Fund Liz Tilberis Scholars Program (W. Ruprecht Wiedemeyer), the Pacific Ovarian Cancer Research Consortium (W. Ruprecht Wiedemeyer and Beth Y. Karlan, Award Number P50 CA083636 from the NIH/National Cancer Institute), The Borden Family Foundation (W. Ruprecht Wiedemeyer), The Garber Foundation (W. Ruprecht Wiedemeyer), an American Cancer Society Early Detection Professorship (Beth Y. Karlan, SIOP-06-258-01-COUN) and a generous donation by Ms. Susie Fragnoli. We thank members of the Cedars-Sinai Women's Cancer Program for critical reading of the manuscript and apologize to authors whose work was not cited.

\section{REFERENCES}

1. Rossof AH, Talley RW, Stephens R, Thigpen T, Samson MK, Groppe C Jr, et al. Phase II evaluation of cis-dichlorodiammineplatinum(II) in advanced malignancies of the genitourinary and gynecologic organs: a Southwest Oncology Group Study. Cancer Treat Rep (1979) 63(9-10):1557-64.

2. Thigpen T, Shingleton H, Homesley H, LaGasse L, Blessing J. cisDichlorodiammineplatinum(II) in the treatment of gynecologic malignancies: phase II trials by the Gynecologic Oncology Group. Cancer Treat Rep (1979) 63(9-10):1549-55.

3. Alberts DS, Green S, Hannigan EV, O'Toole R, Stock-Novack D, Anderson P, et al. Improved therapeutic index of carboplatin plus cyclophosphamide versus cisplatin plus cyclophosphamide: final report by the Southwest Oncology Group of a phase III randomized trial in stages III and IV ovarian cancer. J Clin Oncol (1992) 10(5):706-17.

4. McGuire WP, Hoskins WJ, Brady MF, Kucera PR, Partridge EE, Look KY, et al. Cyclophosphamide and cisplatin compared with paclitaxel and cisplatin in patients with stage III and stage IV ovarian cancer. N Engl J Med (1996) 334(1):1-6. doi:10.1056/NEJM199601043340101 
5. Piccart MJ, Bertelsen K, James K, Cassidy J, Mangioni C, Simonsen E, et al. Randomized intergroup trial of cisplatin-paclitaxel versus cisplatincyclophosphamide in women with advanced epithelial ovarian cancer: threeyear results. J Natl Cancer Inst (2000) 92(9):699-708. doi:10.1093/jnci/92.17. 1446-a

6. Cancer Genome Atlas Research Network. Integrated genomic analyses of ovarian carcinoma. Nature (2011) 474(7353):609-15. doi:10.1038/nature10166

7. Jones S, Wang TL, Shih Ie M, Mao TL, Nakayama K, Roden R, et al. Frequent mutations of chromatin remodeling gene ARID1A in ovarian clear cell carcinoma. Science (2010) 330(6001):228-31. doi:10.1126/science.1196333

8. Wiegand KC, Shah SP, Al-Agha OM, Zhao Y, Tse K, Zeng T, et al. ARID1A mutations in endometriosis-associated ovarian carcinomas. N Engl J Med (2010) 363(16):1532-43. doi:10.1056/NEJMoa1008433

9. Seidman JD, Horkayne-Szakaly I, Haiba M, Boice CR, Kurman RJ, Ronnett BM. The histologic type and stage distribution of ovarian carcinomas of surface epithelial origin. Int J Gynecol Pathol (2004) 23(1):41-4. doi:10.1097/01.pgp.0000101080.35393.16

10. Piccart MJ, Lamb H, Vermorken JB. Current and future potential roles of the platinum drugs in the treatment of ovarian cancer. Ann Oncol (2001) 12(9):1195-203. doi:10.1023/A:1012259625746

11. Matsuo K, Lin YG, Roman LD, Sood AK. Overcoming platinum resistance in ovarian carcinoma. Expert Opin Investig Drugs (2010) 19(11):1339-54. doi:10.1517/13543784.2010.515585

12. Siegel R, Naishadham D, Jemal A. Cancer statistics, 2013. CA Cancer J Clin (2013) 63(1):11-30. doi:10.3322/caac.21166

13. Siddik ZH. Cisplatin: mode of cytotoxic action and molecular basis of resistance. Oncogene (2003) 22(47):7265-79. doi:10.1038/sj.onc.1206933

14. Galluzzi L, Senovilla L, Vitale I, Michels J, Martins I, Kepp O, et al. Molecular mechanisms of cisplatin resistance. Oncogene (2012) 31(15):1869-83. doi:10.1038/onc.2011.384

15. Stewart DJ. Mechanisms of resistance to cisplatin and carboplatin. Crit Rev Oncol Hematol (2007) 63(1):12-31. doi:10.1016/j.critrevonc.2007.02.001

16. Martin LP, Hamilton TC, Schilder RJ. Platinum resistance: the role of DNA repair pathways. Clin Cancer Res (2008) 14(5):1291-5. doi:10.1158/1078-0432. CCR-07-2238

17. Ferry KV, Hamilton TC, Johnson SW. Increased nucleotide excision repair in cisplatin-resistant ovarian cancer cells: role of ERCC1-XPF. Biochem Pharmacol (2000) 60(9):1305-13. doi:10.1016/S0006-2952(00)00441-X

18. Dabholkar M, Bostick-Bruton F, Weber C, Bohr VA, Egwuagu C, Reed E. ERCC1 and ERCC2 expression in malignant tissues from ovarian cancer patients. J Natl Cancer Inst (1992) 84(19):1512-7. doi:10.1093/jnci/84.19.1512

19. Samimi G, Fink D, Varki NM, Husain A, Hoskins WJ, Alberts DS, et al. Analysis of MLH1 and MSH2 expression in ovarian cancer before and after platinum drug-based chemotherapy. Clin Cancer Res (2000) 6(4):1415-21.

20. Murphy MA, Wentzensen N. Frequency of mismatch repair deficiency in ovarian cancer: a systematic review this article is a US Government work and, as such, is in the public domain of the United States of America. Int J Cancer (2011) 129(8):1914-22. doi:10.1002/ijc.25835

21. Helleman J, van Staveren IL, Dinjens WN, van Kuijk PF, Ritstier K, Ewing PC, et al. Mismatch repair and treatment resistance in ovarian cancer. BMC Cancer (2006) 6:201. doi:10.1186/1471-2407-6-201

22. Watanabe Y, Koi M, Hemmi H, Hoshai H, Noda K. A change in microsatellite instability caused by cisplatin-based chemotherapy of ovarian cancer. Br JCancer (2001) 85(7):1064-9. doi:10.1054/bjoc.2001.2037

23. Mao Z, Bozzella M, Seluanov A, Gorbunova V. DNA repair by nonhomologous end joining and homologous recombination during cell cycle in human cells. Cell Cycle (2008) 7(18):2902-6. doi:10.4161/cc.7.18.6679

24. Roy R, Chun J, Powell SN. BRCA1 and BRCA2: different roles in a common pathway of genome protection. Nat Rev Cancer (2012) 12(1):68-78. doi:10.1038/nrc3181

25. Yun MH, Hiom K. CtIP-BRCAl modulates the choice of DNA doublestrand-break repair pathway throughout the cell cycle. Nature (2009) 459(7245):460-3. doi:10.1038/nature07955

26. Wang B, Matsuoka S, Ballif BA, Zhang D, Smogorzewska A, Gygi SP, et al Abraxas and RAP80 form a BRCA1 protein complex required for the DNA damage response. Science (2007) 316(5828):1194-8. doi:10.1126/science.1139476

27. Chen J, Silver DP, Walpita D, Cantor SB, Gazdar AF, Tomlinson G, et al. Stable interaction between the products of the BRCA1 and BRCA2 tumor suppressor genes in mitotic and meiotic cells. Mol Cell (1998) 2(3):317-28. doi:10.1016/S1097-2765(00)80276-2

28. Scully R, Chen J, Ochs RL, Keegan K, Hoekstra M, Feunteun J, et al. Dynamic changes of BRCA1 subnuclear location and phosphorylation state are initiated by DNA damage. Cell (1997) 90(3):425-35. doi:10.1016/S0092-8674(00) 80503-6

29. Marmorstein LY, Ouchi T, Aaronson SA. The BRCA2 gene product functionally interacts with p53 and RAD51. Proc Natl Acad Sci U S A (1998) 95(23):13869-74. doi:10.1073/pnas.95.23.13869

30. Cass I, Baldwin RL, Varkey T, Moslehi R, Narod SA, Karlan BY. Improved survival in women with BRCA-associated ovarian carcinoma. Cancer (2003) 97(9):2187-95. doi:10.1002/cncr.11310

31. Chetrit A, Hirsh-Yechezkel G, Ben-David Y, Lubin F, Friedman E, Sadetzki S. Effect of BRCA1/2 mutations on long-term survival of patients with invasive ovarian cancer: the national Israeli study of ovarian cancer. J Clin Oncol (2008) 26(1):20-5. doi:10.1200/JCO.2007.11.6905

32. Bolton KL, Chenevix-Trench G, Goh C, Sadetzki S, Ramus SJ, Karlan BY, et al. Association between BRCA1 and BRCA2 mutations and survival in women with invasive epithelial ovarian cancer. JAMA (2012) 307(4):382-90. doi:10.1001/jama.2012.20

33. Sakai W, Swisher EM, Karlan BY, Agarwal MK, Higgins J, Friedman C, et al. Secondary mutations as a mechanism of cisplatin resistance in BRCA2-mutated cancers. Nature (2008) 451(7182):1116-20. doi:10.1038/nature06633

34. Swisher EM, Sakai W, Karlan BY, Wurz K, Urban N, Taniguchi T. Secondary BRCA1 mutations in BRCA1-mutated ovarian carcinomas with platinum resistance. Cancer Res (2008) 68(8):2581-6. doi:10.1158/0008-5472.CAN-08-0088

35. Norquist B, Wurz KA, Pennil CC, Garcia R, Gross J, Sakai W, et al. Secondary somatic mutations restoring BRCA1/2 predict chemotherapy resistance in hereditary ovarian carcinomas. J Clin Oncol (2011) 29(22):3008-15. doi:10.1200/JCO.2010.34.2980

36. Borst P, Rottenberg S, Jonkers J. How do real tumors become resistant to cisplatin? Cell Cycle (2008) 7(10):1353-9. doi:10.4161/cc.7.10.5930

37. Aguirre-Ghiso JA. Models, mechanisms and clinical evidence for cancer dormancy. Nat Rev Cancer (2007) 7(11):834-46. doi:10.1038/nrc2256

38. Kaelin WG Jr. The concept of synthetic lethality in the context of anticancer therapy. Nat Rev Cancer (2005) 5(9):689-98. doi:10.1038/nrc1691

39. Farmer H, McCabe N, Lord CJ, Tutt AN, Johnson DA, Richardson TB, et al. Targeting the DNA repair defect in BRCA mutant cells as a therapeutic strategy. Nature (2005) 434(7035):917-21. doi:10.1038/nature03445

40. Audeh MW, Carmichael J, Penson RT, Friedlander M, Powell B, Bell-McGuinn $\mathrm{KM}$, et al. Oral poly(ADP-ribose) polymerase inhibitor olaparib in patients with BRCA1 or BRCA2 mutations and recurrent ovarian cancer: a proof-ofconcept trial. Lancet (2010) 376(9737):245-51. doi:10.1016/S0140-6736(10) 60893-8

41. Fong PC, Yap TA, Boss DS, Carden CP, Mergui-Roelvink M, Gourley C, et al. Poly(ADP)-ribose polymerase inhibition: frequent durable responses in BRCA carrier ovarian cancer correlating with platinum-free interval. J Clin Oncol (2010) 28(15):2512-9. doi:10.1200/JCO.2009.26.9589

42. Ledermann J, Harter P, Gourley C, Friedlander M, Vergote I, Rustin G, et al. Olaparib maintenance therapy in platinum-sensitive relapsed ovarian cancer. N Engl J Med (2012) 366(15):1382-92. doi:10.1056/NEJMoa1105535

43. Turner N, Tutt A, Ashworth A. Hallmarks of 'BRCAness' in sporadic cancers. Nat Rev Cancer (2004) 4(10):814-9. doi:10.1038/nrc1457

44. Quinn JE, James CR, Stewart GE, Mulligan JM, White P, Chang GK, et al. BRCA1 mRNA expression levels predict for overall survival in ovarian cancer after chemotherapy. Clin Cancer Res (2007) 13(24):7413-20. doi:10.1158/ 1078-0432.CCR-07-1083

45. Rajan JV, Wang M, Marquis ST, Chodosh LA. Brca2 is coordinately regulated with Brcal during proliferation and differentiation in mammary epithelial cells. Proc Natl Acad Sci U S A (1996) 93(23):13078-83. doi:10.1073/pnas.93. 23.13078

46. Marks JR, Huper G, Vaughn JP, Davis PL, Norris J, McDonnell DP, et al. BRCA1 expression is not directly responsive to estrogen. Oncogene (1997) 14(1):115-21. doi:10.1038/sj.onc. 1200808

47. Xu CF, Chambers JA, Solomon E. Complex regulation of the BRCA1 gene. J Biol Chem (1997) 272(34):20994-7. doi:10.1074/jbc.272.34.20994

48. Thakur S, Croce CM. Positive regulation of the BRCA1 promoter. J Biol Chem (1999) 274(13):8837-43. doi:10.1074/jbc.274.13.8837 
49. Davis PL, Miron A, Andersen LM, Iglehart JD, Marks JR. Isolation and initial characterization of the BRCA2 promoter. Oncogene (1999) 18(44):6000-12. doi:10.1038/sj.onc. 1202990

50. Bracken AP, Ciro M, Cocito A, Helin K. E2F target genes: unraveling the biology. Trends Biochem Sci (2004) 29(8):409-17. doi:10.1016/j.tibs.2004.06.006

51. Ren B, Cam H, Takahashi Y, Volkert T, Terragni J, Young RA, et al. E2F integrates cell cycle progression with DNA repair, replication, and $\mathrm{G}(2) / \mathrm{M}$ checkpoints. Genes Dev (2002) 16(2):245-56. doi:10.1101/gad.949802

52. Chen D, Pacal M, Wenzel P, Knoepfler PS, Leone G, Bremner R. Division and apoptosis of E2f-deficient retinal progenitors. Nature (2009) 462(7275):925-9. doi:10.1038/nature08544

53. Wenzel PL, Chong JL, Saenz-Robles MT, Ferrey A, Hagan JP, Gomez YM, et al. Cell proliferation in the absence of E2F1-3. Dev Biol (2011) 351(1):35-45. doi:10.1016/j.ydbio.2010.12.025

54. Wu L, Timmers C, Maiti B, Saavedra HI, Sang L, Chong GT, et al. The E2F13 transcription factors are essential for cellular proliferation. Nature (2001) 414(6862):457-62. doi:10.1038/35106593

55. Chen Y, Xu J, Borowicz S, Collins C, Huo D, Olopade OI. c-Myc activates BRCA1 gene expression through distal promoter elements in breast cancer cells. BMC Cancer (2011) 11:246. doi:10.1186/1471-2407-11-246

56. Bilke S, Schwentner R, Yang F, Kauer M, Jug G, Walker RL, et al. Oncogenic ETS fusions deregulate E2F3 target genes in Ewing sarcoma and prostate cancer. Genome Res (2013) 23(11):1797-809. doi:10.1101/gr.151340.112

57. Roussel MF, Davis JN, Cleveland JL, Ghysdael J, Hiebert SW. Dual control of myc expression through a single DNA binding site targeted by ETS family proteins and E2F-1. Oncogene (1994) 9(2):405-15.

58. Llaurado M, Majem B, Castellvi J, Cabrera S, Gil-Moreno A, Reventos J, et al. Analysis of gene expression regulated by the ETV5 transcription factor in OV90 ovarian cancer cells identifies FOXM1 overexpression in ovarian cancer. Mol Cancer Res (2012) 10(7):914-24. doi:10.1158/1541-7786.MCR-11-0449

59. Wu K, Jiang SW, Thangaraju M, Wu G, Couch FJ. Induction of the BRCA2 promoter by nuclear factor-kappa B. J Biol Chem (2000) 275(45):35548-56. doi:10.1074/jbc.M004390200

60. Ciriello G, Miller ML, Aksoy BA, Senbabaoglu Y, Schultz N, Sander C. Emerging landscape of oncogenic signatures across human cancers. Nat Genet (2013) 45(10):1127-33. doi:10.1038/ng.2762

61. Delmore JE, Issa GC, Lemieux ME, Rahl PB, Shi J, Jacobs HM, et al. BET bromodomain inhibition as a therapeutic strategy to target c-Myc. Cell (2011) 146(6):904-17. doi:10.1016/j.cell.2011.08.017

62. Bandopadhayay P, Bergthold G, Nguyen B, Schubert S, Gholamin S, Tang Y, et al. BET bromodomain inhibition of MYC-amplified medulloblastoma. Clin Cancer Res (2014) 20(4):912-25. doi:10.1158/1078-0432.CCR-13-2281

63. Shimamura T, Chen Z, Soucheray M, Carretero J, Kikuchi E, Tchaicha JH, et al. Efficacy of BET bromodomain inhibition in Kras-mutant non-small cell lung cancer. Clin Cancer Res (2013) 19(22):6183-92. doi:10.1158/1078-0432.CCR12-3904

64. Wilson LA, Yamamoto H, Singh G. Role of the transcription factor Ets-1 in cisplatin resistance. Mol Cancer Ther (2004) 3(7):823-32.

65. Macleod K, Mullen P, Sewell J, Rabiasz G, Lawrie S, Miller E, et al. Altered ErbB receptor signaling and gene expression in cisplatin-resistant ovarian cancer. Cancer Res (2005) 65(15):6789-800. doi:10.1158/0008-5472.CAN-04-2684

66. Atlas E, Stramwasser M, Whiskin K, Mueller CR. GA-binding protein alpha/beta is a critical regulator of the BRCAl promoter. Oncogene (2000) 19(15):1933-40. doi:10.1038/sj.onc. 1203516

67. Han B, Mehra R, Dhanasekaran SM, Yu J, Menon A, Lonigro RJ, et al. A fluorescence in situ hybridization screen for E26 transformation-specific aberrations: identification of DDX5-ETV4 fusion protein in prostate cancer. Cancer Res (2008) 68(18):7629-37. doi:10.1158/0008-5472.CAN-08-2014

68. Brenner JC, Ateeq B, Li Y, Yocum AK, Cao Q, Asangani IA, et al. Mechanistic rationale for inhibition of poly(ADP-ribose) polymerase in ETS gene fusionpositive prostate cancer. Cancer Cell (2011) 19(5):664-78. doi:10.1016/j.ccr. 2011.04 .010

69. Wang A, Schneider-Broussard R, Kumar AP, MacLeod MC, Johnson DG. Regulation of BRCA1 expression by the Rb-E2F pathway. J Biol Chem (2000) 275(6):4532-6. doi:10.1074/jbc.275.6.4532

70. Nakayama N, Nakayama K, Shamima Y, Ishikawa M, Katagiri A, Iida K, et al. Gene amplification CCNE1 is related to poor survival and potential therapeutic target in ovarian cancer. Cancer (2010) 116(11):2621-34. doi:10.1002/cncr. 24987
71. Etemadmoghadam D, George J, Cowin PA, Cullinane C, Kansara M, Gorringe $\mathrm{KL}$, et al. Amplicon-dependent CCNE1 expression is critical for clonogenic survival after cisplatin treatment and is correlated with $20 \mathrm{q} 11$ gain in ovarian cancer. PLoS One (2010) 5(11):e15498. doi:10.1371/journal.pone.0015498

72. Koff A, Giordano A, Desai D, Yamashita K, Harper JW, Elledge S, et al. Formation and activation of a cyclin E-cdk2 complex during the G1 phase of the human cell cycle. Science (1992) 257(5077):1689-94. doi:10.1126/science. 1388288

73. Lees E, Faha B, Dulic V, Reed SI, Harlow E. Cyclin E/cdk2 and cyclin A/cdk2 kinases associate with p107 and E2F in a temporally distinct manner. Genes Dev (1992) 6(10):1874-85. doi:10.1101/gad.6.10.1874

74. Dulic V, Lees E, Reed SI. Association of human cyclin E with a periodic G1-S phase protein kinase. Science (1992) 257(5078):1958-61. doi:10.1126/science. 1329201

75. Koff A, Cross F, Fisher A, Schumacher J, Leguellec K, Philippe M, et al. Human cyclin E, a new cyclin that interacts with two members of the CDC2 gene family. Cell (1991) 66(6):1217-28. doi:10.1016/0092-8674(91)90044-Y

76. Ruffner H, Jiang W, Craig AG, Hunter T, Verma IM. BRCA1 is phosphorylated at serine 1497 in vivo at a cyclin-dependent kinase 2 phosphorylation site. $\mathrm{Mol}$ Cell Biol (1999) 19(7):4843-54.

77. Johnson N, Cai D, Kennedy RD, Pathania S, Arora M, Li YC, et al. Cdk1 participates in BRCA1-dependent $S$ phase checkpoint control in response to DNA damage. Mol Cell (2009) 35(3):327-39. doi:10.1016/j.molcel.2009.06.036

78. Johnson N, Li YC, Walton ZE, Cheng KA, Li D, Rodig SJ, et al. Compromised CDK1 activity sensitizes BRCA-proficient cancers to PARP inhibition. Nat Med (2011) 17(7):875-82. doi:10.1038/nm.2377

79. Esashi F, Christ N, Gannon J, Liu Y, Hunt T, Jasin M, et al. CDK-dependent phosphorylation of BRCA2 as a regulatory mechanism for recombinational repair. Nature (2005) 434(7033):598-604. doi:10.1038/nature03404

80. Feldmann G, Mishra A, Bisht S, Karikari C, Garrido-Laguna I, Rasheed Z, et al. Cyclin-dependent kinase inhibitor Dinaciclib (SCH727965) inhibits pancreatic cancer growth and progression in murine xenograft models. Cancer Biol Ther (2011) 12(7):598-609. doi:10.4161/cbt.12.7.16475

81. Parry D, Guzi T, Shanahan F, Davis N, Prabhavalkar D, Wiswell D, et al. Dinaciclib (SCH 727965), a novel and potent cyclin-dependent kinase inhibitor. Mol Cancer Ther (2010) 9(8):2344-53. doi:10.1158/1535-7163.MCT-10-0324

82. Misra RN, Xiao HY, Kim KS, Lu S, Han WC, Barbosa SA, et al. $\mathrm{N}$-(cycloalkylamino)acyl-2-aminothiazole inhibitors of cyclin-dependent kinase 2. N-[5-[[[5-(1,1-dimethylethyl)-2-oxazolyl]methyl]thio]-2-thiazolyl]4- piperidinecarboxamide (BMS-387032), a highly efficacious and selective antitumor agent. J Med Chem (2004) 47(7):1719-28. doi:10.1021/jm0305568

83. Byth KF, Thomas A, Hughes G, Forder C, McGregor A, Geh C, et al. AZD5438, a potent oral inhibitor of cyclin-dependent kinases 1, 2, and 9, leads to pharmacodynamic changes and potent antitumor effects in human tumor xenografts. Mol Cancer Ther (2009) 8(7):1856-66. doi:10.1158/15357163.MCT-08-0836

84. Santamaria D, Barriere C, Cerqueira A, Hunt S, Tardy C, Newton K, et al. Cdk1 is sufficient to drive the mammalian cell cycle. Nature (2007) 448(7155):811-5. doi:10.1038/nature06046

85. Konecny GE, Winterhoff B, Kolarova T, Qi J, Manivong K, Dering J, et al. Expression of p16 and retinoblastoma determines response to CDK 4/6 inhibition in ovarian cancer. Clin Cancer Res (2011) 17(6):1591-602. doi:10.1158/ 1078-0432.CCR-10-2307

86. Finn RS, Dering J, Conklin D, Kalous O, Cohen DJ, Desai AJ, et al. PD 0332991, a selective cyclin D kinase $4 / 6$ inhibitor, preferentially inhibits proliferation of luminal estrogen receptor-positive human breast cancer cell lines in vitro. Breast Cancer Res (2009) 11(5):R77. doi:10.1186/bcr2419

87. Wiedemeyer WR, Dunn IF, Quayle SN, Zhang J, Chheda MG, Dunn GP, et al. Pattern of retinoblastoma pathway inactivation dictates response to CDK4/6 inhibition in GBM. Proc Natl Acad Sci U S A (2010) 107(25):11501-6. doi:10.1073/pnas.1001613107

88. Etemadmoghadam D, Weir BA, Au-Yeung G, Alsop K, Mitchell G, George J, et al. Synthetic lethality between CCNE1 amplification and loss of BRCA1. Proc Natl Acad Sci U S A (2013) 110(48):19489-94. doi:10.1073/pnas.1314302110

89. Ciriello G, Cerami E, Sander C, Schultz N. Mutual exclusivity analysis identifies oncogenic network modules. Genome Res (2012) 22(2):398-406. doi:10.1101/gr.125567.111

90. Aghajanian C, Blessing JA, Darcy KM, Reid G, DeGeest K, Rubin SC, et al. A phase II evaluation of bortezomib in the treatment of recurrent 
platinum-sensitive ovarian or primary peritoneal cancer: a Gynecologic Oncology Group Study. Gynecol Oncol (2009) 115(2):215-20. doi:10.1016/j.ygyno. 2009.07.023

91. Kobrinsky B, Joseph SO, Muggia F, Liebes L, Beric A, Malankar A, et al. A phase I and pharmacokinetic study of oxaliplatin and bortezomib: activity, but doselimiting neurotoxicity. Cancer Chemother Pharmacol (2013) 72(5):1073-8. doi:10.1007/s00280-013-2295-6

92. Miliani de Marval PL, Macias E, Rounbehler R, Sicinski P, Kiyokawa H, Johnson DG, et al. Lack of cyclin-dependent kinase 4 inhibits c-myc tumorigenic activities in epithelial tissues. Mol Cell Biol (2004) 24(17):7538-47. doi:10.1128/MCB.24.17.7538-7547.2004

93. Yu Q, Geng Y, Sicinski P. Specific protection against breast cancers by cyclin D1 ablation. Nature (2001) 411(6841):1017-21. doi:10.1038/35082500

94. Puyol M, Martin A, Dubus P, Mulero F, Pizcueta P, Khan G, et al. A synthetic lethal interaction between K-Ras oncogenes and Cdk4 unveils a therapeutic strategy for non-small cell lung carcinoma. Cancer Cell (2010) 18(1):63-73. doi:10.1016/j.ccr.2010.05.025

95. Kaye SB, Poole CJ, Danska-Bidzinska A, Gianni L, Del Conte G, Gorbunova V, et al. A randomized phase II study evaluating the combination of carboplatinbased chemotherapy with pertuzumab versus carboplatin-based therapy alone in patients with relapsed, platinum-sensitive ovarian cancer. Ann Oncol (2013) 24(1):145-52. doi:10.1093/annonc/mds282

96. Yap TA, Carden CP, Kaye SB. Beyond chemotherapy: targeted therapies in ovarian cancer. Nat Rev Cancer (2009) 9(3):167-81. doi:10.1038/nrc2583

97. Nelson AC, Lyons TR, Young CD, Hansen KC, Anderson SM, Holt JT. AKT regulates BRCA1 stability in response to hormone signaling. Mol Cell Endocrinol (2010) 319(1-2):129-42. doi:10.1016/j.mce.2010.01.019

98. Altiok S, Batt D, Altiok N, Papautsky A, Downward J, Roberts TM, et al. Heregulin induces phosphorylation of BRCA1 through phosphatidylinositol 3-Kinase/AKT in breast cancer cells. J Biol Chem (1999) 274(45):32274-8. doi:10.1074/jbc.274.45.32274

99. Ibrahim YH, Garcia-Garcia C, Serra V, He L, Torres-Lockhart K, Prat A, et al. PI3K inhibition impairs BRCA1/2 expression and sensitizes BRCAproficient triple-negative breast cancer to PARP inhibition. Cancer Discov (2012) 2(11):1036-47. doi:10.1158/2159-8290.CD-11-0348
100. Stecklein SR, Kumaraswamy E, Behbod F, Wang W, Chaguturu V, HarlanWilliams LM, et al. BRCA1 and HSP90 cooperate in homologous and nonhomologous DNA double-strand-break repair and G2/M checkpoint activation. Proc Natl Acad Sci U S A (2012) 109(34):13650-5. doi:10.1073/pnas. 1203326109

101. Rao R, Balusu R, Fiskus W, Mudunuru U, Venkannagari S, Chauhan L, et al. Combination of pan-histone deacetylase inhibitor and autophagy inhibitor exerts superior efficacy against triple-negative human breast cancer cells. Mol Cancer Ther (2012) 11(4):973-83. doi:10.1158/1535-7163.MCT-11-0979

102. Bhalla KN, Rao R, Sharma P, Das Gupta S, Chauhan L, Stecklein S, et al. Treatment with histone deacetylase inhibitors creates 'BRCAness' and sensitizes human triple negative breast cancer cells to PARP inhibitors and cisplatin. Cancer Res (2012) 72(24 Suppl):S3-7. doi:10.1158/0008-5472.SABCS12-S3-7

103. Modesitt SC, Sill M, Hoffman JS, Bender DP. A phase II study of vorinostat in the treatment of persistent or recurrent epithelial ovarian or primary peritoneal carcinoma: a Gynecologic Oncology Group Study. Gynecol Oncol (2008) 109(2):182-6. doi:10.1016/j.ygyno.2008.01.009

Conflict of Interest Statement: The authors declare that the research was conducted in the absence of any commercial or financial relationships that could be construed as a potential conflict of interest.

Received: 07 January 2014; paper pending published: 28 January 2014; accepted: 11 February 2014; published online: 03 March 2014.

Citation: Wiedemeyer WR, Beach JA and Karlan BY (2014) Reversing platinum resistance in high-grade serous ovarian carcinoma: targeting BRCA and the homologous recombination system. Front. Oncol. 4:34. doi: 10.3389/fonc.2014.00034

This article was submitted to Women's Cancer, a section of the journal Frontiers in Oncology.

Copyright (c) 2014 Wiedemeyer, Beach and Karlan. This is an open-access article distributed under the terms of the Creative Commons Attribution License (CC BY). The use, distribution or reproduction in other forums is permitted, provided the original author(s) or licensor are credited and that the original publication in this journal is cited, in accordance with accepted academic practice. No use, distribution or reproduction is permitted which does not comply with these terms. 